\title{
Editorial
}

\section{Back to the future: 10 years of European health reforms}

\author{
ANNA DIXON \\ Director of Policy, The King's Fund, London, UK \\ EMMI POTELIAKHOFF* \\ Policy Fellow, The King's Fund, London, UK
}

\begin{abstract}
The challenges facing European health systems have changed little over 30 years but the responses to them have. Policy ideas that emerged in some countries spread to others; however, the way policies were implemented and the impact they have had has been shaped by specific national contexts. Comparative policy analysis has evolved in response to this, moving away from simple classifications of health systems and crude rankings to studies that try and understand more deeply what works, where and why. For policymakers interested in how other countries have dealt with common challenges, it is important that they avoid the naïve transplantation of policy solutions but understand the need to translate policies to fit the institutional context of a particular country. Policies that cross borders will necessarily be shaped by the social and political institutions of a country. These dimensions should not be ignored in comparative research. The next decade will require health systems to deliver improved care for people with complex needs while at the same time delivering greater value. Policymakers will benefit from looking backwards as well as to their neighbours in order to develop appropriate policy solutions.
\end{abstract}

\section{Introduction}

As the coalition government in England embark on yet another major restructuring of the health system, it may appear to some onlookers that they have learnt little from the past experience of reforming health systems at home or abroad. The advocates of market competition now have near on 20 years of experience to draw on, from the introduction of a purchaser-provider split in the first internal market of the Conservative government in the 1990s (Le Grand

*Correspondence to: Emmi Poteliakhoff, The King's Fund, 11-13 Cavendish Square, London W1G 0AN, UK. Email: e.poteliakhoff@kingsfund.org.uk 
et al., 1998) to the reintroduction of the market by the Labour government in the mid 2000s. As well as looking to their own past, English policymakers could look to the experiences of European neighbours where provider competition has long been a feature of health systems. Yet, there is little reference to other countries in the public or political debate on the reforms. This is despite a growing body of comparative research into health system reforms. This special issue adds to that body of knowledge. The series of articles look at some of the key reform issues that have been pursued across Europe from both a cross-national and interdisciplinary perspective, spanning political science and economics.

The issues preoccupying European countries have changed little over the past 30-40 years with financial pressures, social expectations, concerns about an ageing population and a changing pattern of disease. The responses to these issues have changed, however. This special issue that was commissioned to mark 10 years of the European Health Policy Group, ${ }^{1}$ seeks to reflect on the developments in health policy over the past decade in Europe through a series of research articles and includes some short perspectives on developments in comparative health policy research. The five retrospective articles in this special issue cover many of the major topics that have dominated health policy debates in Europe and internationally over the past 10 years including the role of patient choice (Vrangbaek et al.), hospital reimbursement (O'Reilly et al.), regulation (Helderman et al.), health technology assessment (HTA; Sorenson and Chalkidou) and approaches to chronic disease management (Nolte et al.). Although the timeframe for the articles in this volume was to look back over policy developments and reforms during the 2000s, many of the policy issues and reforms first emerged before this.

\section{Evolution of health care reforms}

It seems almost every decade has seen a crisis in health care precipitated by the economic and fiscal position. The 1970s were dominated by the oil crisis. The response in many member states was to introduce direct and indirect controls on inputs (beds, staff numbers, training places, capital investment), prices (for pharmaceuticals and hospital payments) and volume (items per prescription, sanctions for excessive prescribing). The 1980s saw concerns that aging, technology and rising public expectations were fuelling increases in expenditure as a proportion of gross domestic product - though there is mixed evidence of the

1 The European Health Policy Group (EHPG) is a forum for political scientists and economists to meet regularly to discuss intra- and intercountry analyses of health care systems reform across the different European Union (EU) countries. The first meeting of the EHPG was convened at the London School of Economics and Political Science in September 2000 (Oliver and Mossialos, 2005). The 10th year anniversary meeting of the EHPG was held in September 2010. This special issue is the final output of the articles initially presented at that meeting. 
actual contribution of these factors to rising expenditures (see Mossialos and Le Grand, 1999). In response, countries introduced measures such as expenditure controls and budgets for sectors (pharmaceutical, acute care) and organisations (e.g. sickness funds), and moved away from fee for service and per diem payments to activity-based funding in hospitals and capitation in primary care. The 1980s also saw the rise of technology assessment as an approach to containing costs. Although some countries were early adopters, other countries such as Germany only institutionalised this approach after 2000, as Sorenson and Chalkidou show.

During the 1990s, the dominant health policy questions in many countries including the United Kingdom and the Netherlands centred on the introduction of competition to health systems. Enthoven's ideas crystallised ways of thinking in these countries (Klein, 1999), encouraging the creation of internal markets in health care. In countries with social health insurance models, managed competition, methods of risk adjustment and the definition of essential packages of care were prominent. The key debates focussed on the shifting balance in the role of the state vs market approaches and the role of central government vs local government or non-governmental bodies (Saltman et al., 1998). Rather than a rolling back of the state, these more market-oriented approaches have ironically resulted in growth in the regulatory state as Heldermann et al. trace in England, Italy and the Netherlands. They contrast a new regulatory state that relies on the instrument of regulation to achieve its goals with the former 'dirigiste' state, which used its ownership, planning and centralised administration for these ends. Alongside markets, there was also a greater emphasis on citizen empowerment often manifest in policies to promote patient choice although this was also pursued for instrumental ends as part of competition policies as Vrangbæk et al. demonstrate - as well as other policies to engage citizens in decision making and extend patients' rights.

\section{Evolution of comparative health policy analysis}

In parallel to the evolution of reforms themselves, the comparative analysis of health policy also continues to evolve. There has been growth in the volume of cross-country analysis of health care systems driven by a number of factors. First, the increasing availability of comparative information through the endeavours of organisations such as the Organisation for Economic Co-operation and Development (OECD) and World Health Organisation (WHO). Second, the political imperative is to find new policy ideas to tackle universal concerns such as expenditure growth and the burden of chronic disease. Third, funding through the EU Framework for cross-national research and other cross-national research studies commissioned by the European Observatory on Health Systems and Policies. Finally, the extensive international exchange that now occurs between policymakers across the EU and internationally through intergovernmental 
Ministerial meetings such as those hosted by the Commonwealth Fund and the EU's open method of coordination. ${ }^{2}$

Although these factors have led to more comparative research, it has not necessarily resulted in better comparative research (Øvretveit, 1998). Quantitative studies are plagued by problems over the accuracy of data and the definitions employed limit comparability (Kanavos and Mossialos, 1999) and attempts to benchmark health systems since the WHO's attempt in 2000 are generally greeted with criticism (WHO, 2000; Richardson et al., 2003). As Adam Oliver argues in his perspective such cross-country ranking exercises are a folly. He describes how the outcomes of such exercises are heavily determined by the weights attached to each aspect of a high-performing system and how the appropriate weights to use can plausibly greatly differ from country to country (or person to person). $\mathrm{He}$ therefore urges the reader to treat the results of such exercises with 'a healthy degree of scepticism'. However, how well a country does in such rankings are often picked up by politicians to justify reform and the media to criticise (New York Times, 2007). With comparative datasets widely available, there is nothing to stop researchers from using these data to draw far reaching, sometimes unwarranted conclusions (e.g. Pritchard and Wallace, 2011).

Many comparative studies have tended to be descriptive using case studies to develop classifications (e.g. Roemer, 1976; Field 1988; Anderson, 1989; OECD, 1992, 1994). There is a long history of such case reports that first and foremost describe a country's health system going as far back as the 1920s in reports produced by the League of Nations Health Organisation (the forerunner to WHO; Frey, 1923; Schroetter, 1923). During the past 10 years, the OECD have produced a series of country reports (e.g. OECD, 2008), but more of their activity has been in producing multi-country reports (e.g. OECD, 1992). The European Observatory publishes a series of country profiles following a common template to promote comparability between countries. ${ }^{3}$ In its early years, the European Health Policy Groups focussed on individual country's health systems, seeking to understand how systems had developed and the particular institutional configurations (Oliver and Mossialos, 2005). Over time, the group has sought to promote cross-country analysis.

\section{Bismarck is dead?}

The assumption in the case selection of early cross-national studies was that systems should be compared among similar systems, for example, Bismarck

2 The open method of coordination is a non-legislative tool that aims to encourage Member States to share and coordinate different approaches that address common European challenges. For more information on the open method of coordination and health see European Public Health Alliance 2007.

3 A full list of the European Observatory on Health Systems and Policies Health Systems in Transition Health system profiles (HiTs) is available at http://www.euro.who.int/en/home/projects/observatory/ publications/health-system-profiles-hits 
systems of social health insurance or Beveridge systems with tax funded universal coverage. As Richard Saltman describes in his short perspective, several of the boundaries that previously existed between health system categories have softened and sometimes even melted. Saltman describes how countries with social health insurance funding have substituted taxes or payments for employer/employees contributions and hybrid models have developed in several Central European countries. Josep Figueras, Director of the European Observatory on Health Systems and Policies and head of the WHO European centre on health policy recently argued that “'Beveridge vs Bismarck' is actually a 'dead' debate' and that the key questions currently facing policymakers in Europe will not be answered by only considering the macro level structures of different health systems. Such high-level systems thinking, he argued, is too simplistic and often detached from reality (English health reform: what can we learn from Europe? Seminar held at The King's Fund, 23 March 2011). With the softening of these boundaries, many scholars seek to compare and contrast the implementation of health policies across the old boundary lines where they once felt restricted to select from within these categories.

Nolte et al. focussed on three countries with similar mechanisms of governance and financing - Austria, Germany and the Netherlands - but most of the other articles include countries which span these old divisions.

In their article on choice policies in Northern European health systems, Vrangbæk et al. look at a number of countries including both tax funded and social health insurance funded countries. They examine how the broad, new public management inspired concept of choice spread across Northern Europe. They focus on the initiation, design and implementation of hospital choice policies in England, Sweden, Denmark and the Netherlands. As Vrangbæk et al. describe, policies to give patients greater choice of hospital were based on the idea that markets can ensure the efficient production and allocation of goods and services and that using market-based mechanisms for the delivery of public sector goods, including health care where there will be market imperfections, can beneficial. This broad idea was shared by all four countries analysed by Vrangbæk et al. including both early movers and late introducers. However, specific policy objectives were not necessarily shared by all of the countries; inducing hospitals to provide higher responsiveness in order to retain and attract patients was a principal argument for introducing hospital choice in three of the four countries analysed by Vrangbæk et al. but not for one country, Sweden. Also, although the authors find that patient choice is part of a converging policy trend focussed on empowering patients and the use of market mechanisms in health systems, they also find that institutional structures have resulted in differences in the policy design, implementation and effects of choice in each country.

Helderman et al. focus on regulatory reforms in both 'Bismarck' and 'Beveridge' systems. They demonstrate that institutional arrangements have shaped the implementation of internal market reforms and the regulatory response differently 
in each country. In a thought experiment, the authors raise the possibility that if similar market approaches, that is, competing insurers, were to be adopted, then we might expect regulatory responses to converge. Despite these potential converging trends, history suggests that path dependency and institutional constraints will continue to shape health systems and we can expect health systems to continue to evolve along different lines (Oliver and Mossialos, 2005). In her short perspective, Tuohy takes a positive stance towards these unresolved tensions, asking the reader to join her in the 'dance' that is the comparative study of health policy, a dance "between explanation and prescription, between inductive and deductive analysis, and between attention to converging elements and attention to the continuing distinctiveness of each nation". Although there are common objectives or motivations for introducing the policies, the implementation and institutional arrangements that are put in place differ between countries. The distinctiveness of national policies suggests policies need to be translated rather than transferred.

\section{Policies crossing borders?}

The use of comparative examples by politicians to justify different positions often repeats fallacies rather than facts, as was clear in the use of both the Netherlands as a shining example of managed insurance competition (Okma et al., 2011) and the UK NHS as an abhorrent example of socialised medicine (New York Times, 2009). Ted Marmor warns against naive transplantation the finding of best practice and applying it anywhere - but argues that the differences between countries should not mean that no learning can take place between them. In other words, although there are limits to the transferability of one health policy to another context, this does not mean that policymakers cannot learn from experiences in other countries.

Many of the articles identify 'early adopters' - countries that have led the way on implementing a policy. One might assume that other countries that subsequently introduced similar policies were followers - adopting the policy as a result of seeing it used in another country. Yet, the evidence from these articles suggests that the 'followers' are not simply adopting the policies seen in other countries but are adapting them to fit the political and social institutions into which they are being embedded.

The spread of activity-based funding for hospitals, commonly based on the Diagnosis-Related Group (DRG) classification, can be seen as an example of policy transfer. Activity-based payment, discussed by O'Reilly et al., began in the United States of America during the 1980s and has become the main mechanism for reimbursing hospitals in Europe over the last decade. O'Rielly et al. found that the motivations for introducing activity-based payment were similar across the countries (England, Finland, France, Germany and Ireland) but implementation and development of the policy varied substantially. Activity-based payment appears to be a highly technical tool to benignly raise 
transparency and efficiency but the policy has an increasingly recognised impact on the types of care, which it will encourage, namely hospital-based episodic care as opposed to integrated care for patients with long-term conditions, which crosses organisational boundaries.

Structured approaches to disease management have also been adopted in a number of countries but the context has not always been receptive to their successful implementation. In the three countries on which Nolte et al. focus, the predominant model of care is the structured disease management approach. The authors describe how this model met with many challenges and the experience in these countries is one of limited success. Disease management programmes in these countries have not altered existing structures and integration of nonmedical staff has been limited. The policies did not fundamentally change or even challenge existing structures in the health care system, were overly focussed on specific diseases and were not able to meet the needs of patients with multiple health problems and complex needs. Similar issues were found in a study of case management in the National Health Services (NHS) in England (Rosen et al. 2007) - the policy did not change existing structures in the health care system and was implemented as an 'add on' to existing institutions and incentive structures, limiting its success.

Although technologies may transfer freely, the transfer of institutions is more difficult. The implementation of HTA in most countries involved the creation of new institutions. Sorenson and Chalkidou's reflection on the evolution of HTA in Europe over the last decade gives a detailed account of the development of HTA over time in four countries: England, France, Germany and Sweden. The way in which these new institutions are established, their role, powers and the methods they use, differed across the countries studied by Sorenson and Chalkidou.

Some health policies appear to be based on technical solutions, for example, using DRGs as the basis of activity-based funding of hospitals. However, decisions to adopt a particular technique or methodology may in fact involve political or normative decisions. Although economic evaluation is a method used in some countries as the basis of health technology appraisals, the political environment is important in determining the way in which HTA is implemented. The decision to use HTA at all is normative and there are diverging views on the acceptability of this approach. The originator of HTA, the Office of Technology Assessment in the United States of America, was disbanded mainly due to political hurdles (Sorenson and Chalkidou) and HTA continues to be a controversial issue in the United States of America (Bryan et al. 2009).

Political and social institutions can also influence the pace and extent of implementation. The policies implemented to improve care for people with chronic illness were varied depending on the need to negotiate with multiple actors. In Austria, for example, the implementation of chronic care policies involved negotiation with multiple actors including 21 statutory health insurance funds, which proved challenging for the development of an overarching strategic 
approach (Nolte et al.). The presence of coalition governments rather than stronger majority governments has also led to more incremental reforms in the Netherlands (Helderman et al.).

\section{Conclusions}

Recent data released by the IFS (Institute for Fiscal Studies) shows that health care expenditure has consumed an increasing share of public expenditure in the United Kingdom over 30 years (IFS, 2011). The constraints on public spending in the Euro zone as a result of the financial crisis and continuing debt crisis are likely to bite deeply into publicly funded health care systems. It is not clear that all of the approaches of the past decade will survive this squeeze. Activity-based funding for hospitals in some countries was used to contain costs in a shift away from fee for service and per diem payments, in others such as England it was to encourage activity in order to tackle waiting times and to reward hospitals for attracting patients. Payors, including insurer, sickness funds and local authority purchasers and commissioners, will be seeking new ways of transferring financial risk to providers as well as rewarding quality. However, measures such as HTA aimed at containing cost will no doubt continue to play a significant role as questions are asked about the comprehensiveness of coverage and whether priorities have to be set.

Although growth in the proportion of the population who are old is still often cited as a key challenge for health systems, it is clearer now that the challenge comes from the increasing burden of chronic illness, in particular multiple comorbidities and people with complex social and health care needs. Solutions to the challenge of caring for people with multiple chronic illnesses have eluded governments for so long but will be essential if the health systems are to meet the needs of patients for the next decade.

Many of the approaches required to deliver better care of people with chronic illness are in tension with existing institutions and incentive structures, including those put in place under the policies discussed in the first four articles. For example, activity-based payment encourages more hospital activity rather than the prevention of admissions and provision of care outside of the acute hospital. Patient choice of hospital provider at the point of referral may encourage fragmentation of the patient pathway, when these patients need coordinated and integrated care.

Looking back over a decade of health reforms, it is interesting to note that there is very little new under the sun. This suggests there will continue to be value in looking back in order to look ahead to solving the challenges of the next 10 years. If, like Ted Marmor, you believe that despite our differences there is value in learning from our neighbours then it also suggests a continued demand for cross-country health policy research and analysis that can help policymakers find solutions to the common challenges we face. 


\section{References}

Anderson, O. W. (1989), The Health Services Continuum in Democratic States: An Inquiry into Solvable Problems, Ann Arbor, MI, USA: Health Administration Press.

Bryan, S., S. Sofaer, T. Siegelberg and M. Gold (2009), 'Has the time come for cost-effectiveness analysis in US health care?', Health Economics, Policy and Law, 4: 425-443.

Field, M. G. (1988), Success and Crisis in National Health Systems: A Cross-national Approach, London: Routledge.

Frey, G. (1923), Public Health Services in Germany, Geneva: League of Nations Health Organisation, notes found in overview $\backslash$ notes $\backslash$ histnotes.doc

IFS (2011). The changing composition of public spending Institute for Fiscal Studies 2011 (authored by Rowena Crawford and Paul Johnson), http://www.ifs.org.uk/bns/ bn119.pdf

Kanavos, P. and E. Mossialos (1999), 'International comparisons of health care expenditures: what we know and what we do not know', Journal of Health Services Research and Policy, 4(2PC): 122-126.

Klein, R. (1999), 'Markets, politicians and the NHS Enthoven's analysis still illuminates the NHS', British Medical Journal, 319(7222): 1383-1384, http://www.ncbi.nlm.nih.gov/ pmc/articles/PMC1117121/ [3 October 2011].

Le Grand, J., N. Mays and J. A. Mulligan (1998), Learning from the NHS Internal Market: a Review of the Evidence, London: King's Fund.

Mossialos, E. and J. Le Grand (1999), 'Cost Containment in the EU: an Overview', in E. Mossialos and J. Le Grand (eds), Health Care and Cost Containment in the European Union, Aldershot, UK: Ashgate, 1-154, ISBN 1840144033.

New York Times (2007), 'America’s lagging health care system', Editorial, 1 November 2007, http://www.nytimes.com/2007/11/01/opinion/01thu3.html?scp=4\&sq= commonwealth + fund\&st $=$ nyt [3 October 2011].

New York Times (2009), 'Stephen Hawking defends care in Britain', Bernie Becker, August 12, 2009, http://prescriptions.blogs.nytimes.com/2009/08/12/stephen-hawkingdefends-care-in-the-uk/?scp=3\&sq= socialized $\% 20$ medicine $\% 20$ death $\% 20$ panel $\&$ st $=$ cse [3 October 2011].

Organisation for Economic Co-operation and Development (OECD) (1992), The Reform of Health Care: a Comparative Analysis of Seven OECD Countries, 2nd edn. Paris: OECD.

OECD (1994), The Reform of Health Care Systems: a Review of Seventeen Countries, Paris: OECDBK.

OECD (2008), 'OECD reviews of health systems: Turkey 2008', http://www.oecd-ilibrary. org/social-issues-migration-health/oecd-reviews-of-health-systems_19901410 [3 October 2011].

Okma, K. G., T. R. Marmor and J. Oberlander (2011), 'Managed competition for Medicare? Sobering lessons from the Netherlands', The New England Journal of Medicine, 365(4): 287-289.

Oliver, A. and E. Mossialos (2005), 'European health systems reforms: looking backward to see forward'?, Journal of Health Politics, Policy and Law, 30(1-2): 7-28.

Øvretveit, J. (1998), Comparative and Cross-Cultural Health Research: a Practical Guide, Abingdon, Oxon, UK: Radcliffe Medical Press.

Pritchard, C. and M. S. Wallace (2011), 'Comparing the USA, UK and 17 Western countries' efficiency and effectiveness in reducing mortality', Journal of the Royal Society of Medicine Short Reports, 2(7): 60, doi:10.1258/shorts.2011.011076 
Richardson, J., J. Wildman and I. K. Robertson (2003), 'A critique of the World Health Organisation's evaluation of health system performance', Health Economics, 12(5): 355-366.

Rosen, R., P. Asaria and A. Dixon (2007), Improving Chronic Disease Management: an Anglo-American Exchange, London: King's Fund.

Roemer, M. I. (1976), Health Care Systems in World Perspective, Ann Arbor, MI, USA: Health Administration Press.

Saltman, R. B., J. Figueras and C. Sakellarides (1998), Critical Challenges for Health Care Reform in Europe, Philadelphia: Open University Press, ISBN: 0335199704/0-33519970-4.

Schroetter, H. (1923), Public Health Services in Austria, Geneva: League of Nations Health Organisation.

The World Health Report (2000), 'Health Systems: Improving Performance'. Geneva: World Health Organization, http://www.who.int/whr/2000/en/ [3 October 2011]. 